\title{
SISTEM PEMERINTAHAN PRESIDENSIAL DI INDONESIA PRESPEKTIF FIQH SIYASAH DUSTURIYAH
}

\author{
Astri Wulandari' ${ }^{1}$, Zainuddin² \\ ${ }^{1}$ Institut Agama Islam Negeri Batusangkar \\ e-mail: astriw218@gmail.com \\ 2Institut Agama Islam Negeri Batusangkar \\ e-mail: zainuddin@iainbatusangkar.ac.id
}

\begin{abstract}
This study discusses the review of Islamic Constitutional Law on presidential government systems in Indonesia. This type of research is library research in which materials are collected through books, laws and journals related to research. The method used is a normative legal research method. Theories used are power theory, authority theory, trias politica theory and tanfidriyyah sulthah theory. From the results of the research conducted by the author, it can be concluded that based on the Indonesian constitution namely the 1945 Constitution in Article 4 paragraph (1) the power of the President includes executive, legislative and judicial powers. In a presidential government system the President is not only the head of state but also the head of government. Based on the Sulfah tanfidrivyah review of the power of the head of state in the presidential system in Indonesia, namely the power of the head of state in the presidential government system does not conflict with Islamic governance and Islamic law because in the Fiqh Siyasah Dusturiyah or the Khalifah Islamic State Constitutional Law covers all power, both as head of state, head of state government, legislature, judiciary and head of religion. It's just that presidential power in the Presidential system does not include as head of religion.
\end{abstract}

Keywords: Sulthah Tanfidriyyah, Khalifah, Sistem Presidensial, Hukum Tata Negara Islam

\section{PENDAHULUAN}

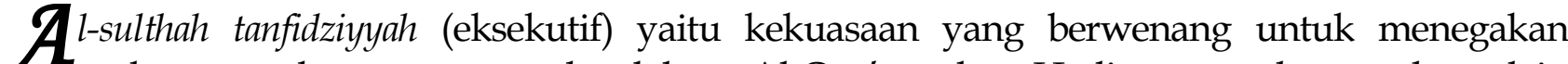
pedoman-pedoman yang ada dalam Al-Qur'an dan Hadis, atau dengan kata lain kekuasaan ini berfungsi untuk melaksanakan undang- undang. Dalam bahasa modern, lembaga ini meliputi kepala Negara, menteri- menteri dan seluruh pegawai kementrian. Tujuan lembaga ini yaitu untuk menegakkan pedoman-pedoman Tuhan yang disampaikan melalui Al-Qur'an dan sunnah serta untuk menyiapkan masyarakat agar mengakui dan menjelaskan pedoman-pedoman yang telah dianjurkan dalam kehidupan berbangsa. (Al Maududi, 1990: 246)

Lembaga ini merupakan lembaga yang berperan penting dalam suatu Negara, oleh karena itu kaum muslimin (masyarakat) diwajibkan untuk menaati serta menjunjung tinggi perintahnya dengan syarat lembaga ini mentaati segala ketentuan Allah dan Rasul-Nya serta menghindari dari dosa besar.

Al-sulthah tasri'iyyah (legislatif) merupakan lembaga pemerintahan yang secara terminologi fiqih disebut lembaga penengah dan pemberi fatwa. Yang di negara- negara modern disebut dengan Dewan Perwakilan Rakyat (DPR) atau Majelis Permusyawaratan Rakyat (MPR). Kekuasaan yang berwenang membuat undang-undang atau lembaga pemegang wewenang memberi fatwa. Keputusan mereka tidak boleh bertentangan dengan AlQur'an dan Hadis. (Al Mubarok, 1995: 92) Al-sulthah qadhaiyyah (yudikatif) merupakan kekuasaan kehakiman yang mengadili setiap pelanggaran undang-undang. Kekuasaan ini 
harus terpisah, bersifat bebas dan terlepas dari campur tangan badan lain, sehingga dapat membuat keputusan yang benar dan murni tanpa ada pengaruh dari manapun. (Al Maududi, 1984: 245)

Dalam konsep hukum Islam, hal-hal yang berkaitan dengan pembagian kekuasaan dibahas dalam fiqh siyasah dusturiyah. Dalam fiqh siyasah dusturiyah, badan negara yang bertugas memusyawarahkan kepentingan rakyat dikenal dengan istilah "Majlis Syura" atau "ahl al-halli wa al-aqdi" atau seperti yang disebut Abu A'la al-Maududi sebagai "Dewan Penasehat" dan al-Mawardi menyebutnya dengan ahl al-Ikhtiyar. (Gurmansyah, 2017: 125) Implementasi pembagian kekuasaan ini dapat dilihat pada masa khulafaurrasyidin. Saat itu kekuasaan eksekutif dipegang oleh seorang khalifah, kekuasaan legeslatif dipegang oleh Majelis Syura, dan kekuasaan yudikatif dipegang oleh qadhi atau hakim. Kemudian, pada masa khilafah kedua yaitu Umar bin Khattab, pembagian kekuasaan antara eksekutif, legeslatif, dan yudikatif dirinci lewat undang-undang. Pada masa ini juga, Umar bin Khattab membuat undang-undang yang memisahkan antara kekuasaan eksekutif dan legeslatif, dengan tujuan agar para qadhi sebagai pemegang kekuasaan yudikatif dalam memutuskan perkara bisa bebas dari pengaruh eksekutif. (Gurmansyah, 2017: 124)

Di Indonesia kepala negara dan kepala pemerintahan berada di tangan Presiden, sehingga menurut konstitusi ketatanegaraan ini, kepala pemerintah hakikatnya adalah presiden. Sistem ketatanegaraan di mana kepala pemerintahan ada di tangan Presiden dapat dinamakan "Sistem Presidentil". (Joeniarto, 1996: 188) Sitem pemerintahan Presidensial di Indonesia dapat dikaji menurut menurut teori sulthah tanfiziyah dalam sistem pemerintahan Islam.

Sebagai lembaga yang sangat penting di suatu negara Islam, al-sulthah al-tanfidziyyah tentunya memiliki batasan kekuasaan bagi kepala negara atau penguasanya. Begitu juga pada sistem pemerintahan presidensial pada negara Indonesia yang juga memiliki batasan kekuasaan untuk kepala negara, berdasarkan hal tersebut penulis tertarik untuk menggali lebih dalam bagaimana tinjauan Fiqh siyasah Dusturiyah terhadap sistem pemerintahan di Indonesia.

\section{METODE PENELITIAN}

Jenis penelitian yang digunakan dalam adalah penelitian kepustakaan (library research) Penulis menggunakan metode penelitian hukum normatif untuk membahas permasalahan tersebut. Dalam hal ini penulis menggunakan UUD 1945 sebagai acuan utamanya dan Fiqh Siyasah Dusturiyah. Penulis juga menggunakan metode kajian fikih dengan menggunakan dalil-dalil, baik Alqur'an maupun Hadis, kemudian menarik kesimpulan hukum dari dalil-dalil tersebut.

\section{HASIL DAN PEMBAHASAN}

\section{Presiden sebagai Kepala Negara}

Sebagai kepala negara, Presiden tentunya memiliki tugas-tugas yang harus dilakukan sebagai kewenangannya. Kekuasaan Presdien sebagai kepala negara yang berdasarkan undang-undang dasar 1945 yaitu: (a) Presiden memegang kekuasaan tertinggi angkatan darat, 
angkatan laut dan angkatan udara (UUD 1945 Pasal 10); (b) Presiden mengangkat duta dan konsul (UUD 1945 Pasal 13 ayat 1); (c) Presiden menerima penempatan duta negara lain dengan menerima pertimbangan Dewan Perwakilan Rakyat (UUD 1945 Pasal 13 ayat 3); (d) Negara menjamin kebebasan masing-masing penduduk untuk memeluk agamanya masingmasing dan untuk beribadat menurut agama dan kepercayaannya itu (UUD 1945 Pasal 29 ayat 2); (e) Negara memprioritaskan anggaran pendidikan sekurang-kurangnya dua puluh persen dari anggaran pengeluaran dan pengeluaran daerah untuk memenuhi kebutuhan penyelenggaraan pendidikan nasional (UUD 1945 Pasal 31 ayat 4); (f) Negara memajukan budaya nasional Indonesia di tengah peradaban dunia dengan menjamin kebebasan masyarakat dalam mendukung dan mengembangkan nilai-nilai budayanya (UUD 1945 Pasal 32 ayat 1); (g) Negara penghormatan dan mendukung bahasa daerah sebagai kekayaan budaya nasional (UUD 1945 Pasal 32 ayat 2); (h) Fakir miskin dan anak-anak terlantar dipelihara oleh negara (UUD 1945 Pasal 34 ayat 1); (i) Negara mengembangkan sistem jaminan sosial untuk seluruh rakyat dan memberdayakan masyarakat yang lemah dan tidak mampu sesuai dengan martabat kesejahteraan (UUD 1945 Pasal 34 ayat 2); dan (j) Negara yang bertanggung jawab atas penyediaan layanan kesehatan dan fasilitas pelayanan umum yang layak (UUD 1945 Pasal 34 ayat 3$)$.

Berdasarkan kekuasaan presiden di atas apabila dilihat berdasarkan pandangan sulthah tanfidziyyah, yaitu kekuasaan presiden sebagai kepala negara pada sistem Presidensial sudah sesuai dengan syariat Islam karena di dalam ketatanegraan Islam kekuasaan tertinggi adalah khalifah yang berperan selain sebagai kepala negara dan sebagai kepala pemerintahan sekaligus pemimpin agama. Dalam ketatanegaraan Islam juga mengatur seluruh ketentuan yang dapat mensejahterakan umat seperti fakir miskin dan anak terlantar dipelihara dan dilindungi. Hal ini dapat dilihat dengan adanya ayat-ayat Al-Quran dan Hadis yang berbicara mengenai fakir miskin. Seperti dalam Q.S At-Taubah ayat 60, Q.S Ar-rum ayat 38, Q.S An-nisa ${ }^{\text {ee }}$ ayat 135, Q.S Al-An"a, ayat 52. Maka dalam hal ini kekuasaan Presiden sebagai kepala negara sudah sesuai berdasarkan sulthah tanfidziyyah.

\section{Presiden sebagai kepala Pemerintahan}

Dalam menjalankan tugasnya sebagai kepala pemerintahan, tentunya Presiden mempunyai landasan atau dasar sebagai pedoman dalam menjalankan roda pemerintahan suatu negara. Kekuasaan Presiden sebagai kepala pemerintahan yang tertuang di dalam undang-undang sebagai berikut:

1. Presiden Republik Indonesia memegang kekuasaan pemerintahan menurut undangundang dasar (UUD 1945 Pasal 4 ayat 1);

2. Presiden menetapkan peraturan pemerintah untuk menjalankan undang-undang sebagaimana mestinya (UUD 1945 Pasal 5 ayat 2);

3. Menteri-menteri diangkat dan diberhentikan oleh Presiden (UUD 1945 Pasal 17 ayat 2);

4. Hubungan wewenang antara pemerintah pusat dan pemerintah daerah provinsi, kabupaten, dan kota atau provinsi dan kabupaten dan kota, diatur dengan undang-undang dengan memperhatikan kekhususan dan keanekaragaman daerah (UUD 1945 Pasal 18B ayat 1); 
5. Hubungan keuangan, pelayanan umum, sumber daya alam dan sumber daya lain antara pemerintah pusat dan pemerintah daerah pengaturan dan pelaksanaan yang adil dan selaras berdasarkan undang-undang (UUD 1945 Pasal 18B ayat 2);

6. Presiden mengesahkan rancangan undang-undang yang telah disetujui bersama untuk menjadi undang-undang (UUD 1945 Pasal 20 ayat 4);

7. Rancangan undang-undang anggaran dan belanja negara yang disetujui oleh presiden untuk disetujui bersama Dewan Perwakilan Rakyat dengan memperhatikan pertimbangan Dewan Perwakilan Daerah (UUD 1945 Pasal 23 ayat 2);

8. Anggota Badan Pemeriksa Keuangan dipilih oleh Dewan Perwakilan Rakyat dengan mepertimbangkan Dewan Perwakilan Daerah dan diresmikan oleh Presiden (UUD 1945 Pasal 23F ayat 3);

9. Calon Hakim Agung meminta Komisi Yudisial kepada Dewan Perwakilan Rakyat untuk mendapatkan persetujuan dan selanjutnya ditetapkan sebagai hakim agung oleh Presiden (UUD 1945 Pasal 24A ayat 3);

10. Anggota Yudisial diangkat dan diberhentikan oleh Presiden dengan persetujuan Dewan Perwakilan Rakyat (UUD 1945 Pasal 24B ayat 3);

11. Mahkamah Konstitusi memiliki sembilan orang anggota pengadilan yang ditetapkan oleh Presiden, yang diajukan masing-masing oleh tiga orang oleh Mahkamah Agung, tiga orang oleh Dewan Perwakilan Rakyat, dan tiga orang oleh Presiden (UUD 1945 Pasal 24C ayat 3);

12. Perlindungan, pemajuan, penegakan dan pemenuhan hak asasi manusia adalah tanggung jawab negara, memerlukan pemerintahan (UUD 1945 Pasal 28I ayat 4);

13. Setiap warga negara wajib mengikuti pendidikan dasar dan pemerintahan wajib mebiayainya (UUD 1945 Pasal 31 ayat 2);

14. Pemerintah mengusahakan dan mengatur satu sistem pendidikan nasional, yang meningkatkan keimanan dan ketakwaan serta akhlak mulia dalam rangka mencerdaskan kehidupan bangsa, yang mengatur dengan undang-undang (UUD 1945 Pasal 31 ayat 3); dan

15. Pemerintah memajukan ilmu pengetahuan dan teknologi dengan menunjang tinggi nilainilai agama dan persatuan bangsa demi kemajuan peradaban serta kesejahteraan umat manusia (UUD 1945 Pasal 31 ayat 5)

Berdasarkan kekuasaan presiden di atas apabila dilihat berdasarkan pandangan sulthah tanfidziyyah, di mana kekuasaan presiden sebagai kepala pemerintahan dalam sistem Presidensial sudah sesuai dengan syariat Islam karena berdasarkan kekuasaan khalifah dalam ketatanegaraan Islam yaitu mengepalai kekuasaan pemerintahan (tanfizu al-ahkam). Dengan kekuasaan ini kepala negara merupakan sebagai intansi tertinggi dan kekuasaan eksekutif dalam menjalankan roda pemerintahan. Khalifah dalam ketatanegaraan Islam melaksanakan kekuasaan eksekutif tertinggi dan mencerminkan rakyat dalam kepemimpinan politiknya, kekuasaannya yang bersumber dari rakyat serta syari'at Islam.

\section{Presiden Sebagai Pemegang Kekuasaan Legislatif}

Presiden dalam pemegang kekuasaan legislative juga berperan dalam pembentukan undang-undang serta memajukan rencana Undang- Undang dan mengesahkan suatu UndangUndang. Meskipun kekuasaan pembentukan undang-undang merupakan wilayah lembaga legislatif/DPR, namun Presiden tetap mendapatkan peran yang sangat penting karena UUD 
1945 mengatur bahwa setiap rancangan undang- undang dibahas oleh Dewan Perwakilan Rakyat dan Presiden untuk mendapat persetujuan bersama.

Dalam hal ini jika dilihat berdasarkan sulthah tanfidziyyah, dalam ketatanegaraan Islam seorang khalifah juga berwenang menetapkan suatu undang-undang (iqamatul al-hudud), di mana Khalifah menjalankan kekuasaan legislativenya dengan menegakan supremasi hukum, sehingga dapat memelihara hukum-hukum Allah dan menjaga hak-hak umat. Selain itu juga menerapkan undang-undang yang ada di dalam Al-qur'an dan Sunnah Rasul SAW termasuk ijtihad atau fatwa ulama.

\section{Presiden Sebagai Pemegang Kekuasaan Yudikatif}

Presiden dalam kekuasaan yudikatifnya dapat memberikan grasi dan amnesti dalam keadaan tertentu. Dalam hal ini jika dipandang berdasarkan sulthah tanfidziyyah kekuasaan Presiden dalam memberikan grasi maupun amnesti sudah sesuai dengan syariat Isam, dikarenakan Islam adalah agama yang senantiasa mementingkan kemaslahatan serta kebahagiaan bagi seluruh manusia, baik itu dalam tujuan hidup di dunia bahkan di akhirat. Pada prinsipnya pengampunan dan pemaafan sangatlah dianjurkan oleh Islam.

Apabila dilihat dari sistem ketatanegaraan Islam, Khalifah adalah pemegang kendali pemimpin umat, segala jenis kekuasaan berpuncak padanya dan segala garis politik agama dan dunia bercabang dari jabatannya, karena itulah Khalifah merupakan kepala pemerintahan yang bertugas menyelenggarakan undang-undang untuk menegakkan Islam dan mengurus Negara dalam bingkai Islam.

Kewenangan seorang Presiden adalah sebagai kepala pemerintahan dan sekaligus sebagai kepala negara. Dua kewenangan sebagai kepala negara dan kepala pemerintahan inilah yang saat ini disandang Presiden Republik Indonesia. Dalam sistem presidensil, tidak dibedakan apakah Presiden adalah sebagai kepala Negara atau kepala pemerintahan. Akan tetapi, yang ada hanya Presiden dan wakil Presiden saja dengan segala hak dan kewajibannya atau tugas dan kewenangannya masing-masing. (Sumali, 2003: 41) Sebagai kepala negara yang bertindak untuk dan atas nama negar ditentukan dalam Pasal 10, Pasal 11, Pasal 12, Pasal 13, Pasal 14, dan Pasal 15 UUD 1945. Dua kewenangan tersebut ada pada satu tangan dan tunggal, yaitu di tangan Presiden Republik Indonesia.

Dalam ketatanegaraan Islam seorang khalifah memiliki 10 (sepuluh) kewajiban, yang mana terdapat kewajiban seorang pemimpin menegakkan supremasi hukum (hudûd) untuk melindungi larangan- larangan Allah swt dari upaya-upaya pelanggaran terhadap larangan tersebut, dan melindungi hak-hak hamba-Nya dari upaya pelanggaran dan perusakan terhadapnya.( Al-Mawardi, 2019: 25)

Kekuasaan Presiden dalam sistem Presidensial yaitu di mana seorang presiden memiliki kewenangan yang memiliki otoritas langsung sebagai pemegang kekuasaan eksekutif dan tidak hanya sebagai penyelenggara saja. Hal tersebut juga merupakan posisi Presiden yang dipilih secara langsung oleh rakyatnya. Maka sistem Presidensial di Indonesia merupakan sebuah gagasan bagi pembangunan demokrasi yang menempatkan Presiden sebagai pemegang kekuasaan eksekutif. Akan tetapi skekuasaan seorang Presiden tetaplah berdasarkan konstitusi yang berlaku.

Apabila dicermati kembali kekuasaan kepala negara dalam Islam melebihi kekuasaan Presiden dalam sistem presidensial, maka dapat dilihat bahwa menurut Hukum Tata Negara 
Islam menyetujui konsep/sistem presidensial, karena khlaifah di samping memiliki kekuasaan eksekutif juga memiliki kekuasaan legislatif dan yudikatif. Di samping itu Sistem presidensial di Indonesia juga sejalan dengan sistem ketatanegaraan Islam atau sulthah tanfidziyyah, karena baik dalam sistem presidensial yang ada di Indonesia maupun sistem ketatanegaraan Islam memiliki peran serta tujuan yang sama yaitu untuk mewujudkan tujuan kepemimpinan agar terealisasikan dalam bentuk nyata yang dapat mensejahterakan rakyat serta sesuai dengan ketentuan syari'at Islam. Namun yang menjadi perbedaan mendasar antara konstitusi Indonesia dengan Islam yaitu terletak pada dari mana aturan atau sumber itu berasal. Dalam konstitusi kekuasaan Presiden dibatasi oleh UUD 1945, sementara dalam Islam langsung bersumber dari Al-Quran dan Sunnah. Sehingga Presiden tidak memiliki kekuasaan kepemimpinan agama, sedangkan khalifah memilikinya.

\section{KESIMPULAN}

Berdasarkan konstitusi Indonesia yaitu Undang-undang Dasar 1945 pada Pasal 4 ayat (1) kekuasaan Presiden meliputi kekuasaan eksekutif, legislatif dan yudikatif. Dalam sistem pemerintahan presidensial Presiden tidak hanya sebagai kepala negara melainkan sekaligus kepala pemerintahan. Dalam penerapan kekuasaan Presiden dalam sistem presidensial sudah sesuai dengan Hukum Tata Negara Islam dan syariat Islam.

Berdasarkan tinjauan sulthah tanfidziyyah terhadap kekuasaan kepala negara dalam sistem presidensial di Indonesia yaitu kekuasaan kepala negara pada sistem pemerintahan Presidensial tidak bertentangan dengan ketatanegaraan Islam serta syariat Islam karena dalam Fiqh Siyasah Dusturiyah atau Hukum Tata Negara Islam khalifah meliputi seluruh kekuasaan, baik sebagai kepala negara, kepala pemerintahan, legislatif, yudikatif maupun kepala agama. Hanya saja kekuasaan presiden dalam tidak mencakup sebagai kepala agama. Dalam hal ini terlihat bahwa kekuasaan khalifah lebih luas dari kekuasaan presiden dalam sistem presidensial di Indonesia akan tetapi dalam penerapannya sudah sesuai dengan ketatanegaraan Islam.

\section{DAFTAR PUSTAKA}

Al Maududi, A. A. (1984). Khalifah dan Kerajaan. Bandung: Mizan.

Al Maududi, A. A. (1990). Sistem Politik Islam. Bandung: Mizan.

Al Mubarok. (1995). Sistem Pemerintahan dalam Perspektif Islam. terj. Firman Harianto. Jakarta: Pustaka Mantik.

Al-Mawardi, A. H. A. M. H. B. (2006). Al-Ahkam as-Sulthaniyah, Dar al-Hadis, al-Qahirah Al-Mawardi, I. (2019). Ahkam Sulthaniyah: Sisitem Pemerintahan Khalifah Islam. terj:

Khalifurahman Fath \& Faturrahman. Jakarta: Qisthi Press.

Az-Zuhaili, W. (2011). Fikih Islam Waadillatuhu. Jakarta: Gema Insani.

Budiarjo, M. (2008). Dasar-dasar Ilmu Politik. Jakarta: Penerbit Gramedia pustaka Utama.

Djaelani, A. Q. (1995). Negara Ideal, Negara Ideal Menurut Konsepsi Islam. Surabaya: Bina Ilmu.

Farhah \& A. F. (2013). Prinsip Etika Politik Pemimpin Dalam Islam, 4 (2): 80. 
Fatahullah, J. (2014). Studi Ilmu Politik. Yogyakarta: PT. Graha Ilmu.

Gaffar, A. (2006). Politik Indonesia, Transisi menuju Demokrasi. Yogyakarta: Pustaka Pelajar.

Gurmasyah, W. (2017). Trias Politica dalam Perspektif Fikih Siyasah. 2(2): 124.

Hidjaz. (2003). Khalifah Dalam Islam. 12 (9): 122.

Iqbal, M. (2014). Figh Siyasah Kontekstualisasi Doktrin Politik Islam. Jakarta: Kencana.

Joeniarto. (1996). Sejarah Ketatanegaraan Republik Indonesia. Jakarta: Bumi Aksara.

Komaruddin. (2017). Teori Kewenangan. 3(3): 26.

Magwasar, A. (2013). Khalifah dan Qanun Dalam Islam. Surabaya: Digilib UIN Sunan Ampel.

Munawwir, A. W. (1997). Kamus Al-munawwir, Arab Indonesia. Surabaya: Pustaka Progresif.

Muntoha. (1996). Kriteria Kepala Negara dalam Sistem Politik Islam (Telaah SosioHistoris Terhadap Hadits Politik). Yogyakarta: Universitas Islam Indonesia.

Prabandani, H. W. (2015). Batas Konstitusional Kekuasaan Eksekutif Presiden (Constitutional Limits Of The Presidential Executive Power). 12 (03): 267.

Pulungan, S. J. (1996). Prinsip-prinsip Pemerintahan dalam Piagam Madinah Ditinjau dalam Pandangan Al-Qu'an. Jakarta: Raja Grafindo Persada.

Pulungan, S. J. (1997). Fiqh Siyasah: Ajaran, Sejarah dan Pemikiran. Jakarta: PT. Raja Grafindo Persada.

Ranadireksa, H. (2007). Visi Bernegara: Arsitektur Konstitusi Demokratik, Mengapa Ada Negara Yang Gagal Melaksanakan Demokrasi. Bandung: Fokusmedia.

Sjadzah, M. (1993). Islam dan Tata Negara: Ajaran, Sejarah, dan Pemikiran. Jakarta: UI Press.

Undang-Undang Dasar Negara Republik Indonesia pasal 4 ayat (1) Tentang Kekuasaan Pemerintah Negara.

Undang-Undang Dasar Negara Republik Indonesia Tahun 1945 Pasal 7A BAB III Tentang Kekuasaan Pemerintahan.

Undang-Undang Dasar Negara Republik Indonesia Tahun 1945, Sekretariat Jenderal MPR RI 2002.

Undang-Undang Dasar Negara Republik Indonesia, Sekretariat Jenderal MPR RI 2002

Undang-Undang Negara Republik Indonesia Nomor 3 Tahun 2002 Tentang Pertahanan Negara.

Yustiana. (2017). Konsep Kementrian (Al-Wizarah) Imam Al-Marwardi dan Relevansinya Terhadap Sistem Pemerintahan Kontemporer. Skripsi. Universitas Islam Negeri Raden Intan Lampung.

Zamroni, M. (2015). Jurnal Kekuasaan Presiden Dalam Mengeluarkan Perppu (President's Authority To Issue Perppu). 